\title{
Patients attitude towards surgeons attire in Our Lady of Lourdes Hospital Drogheda
}

\author{
Babak Meshkat ${ }^{1^{*}}$, Gary Allan Bass ${ }^{1}$, Melania Matcovici ${ }^{2}$, Zarah Farnes ${ }^{3}$, Claire Buckley ${ }^{3}$, Omar Al Saffar ${ }^{3}$, \\ Peter Gillen ${ }^{1,3}$
}

\begin{abstract}
Background: A doctor's competence and professionalism is often judged on the basis of attire. Our Lady of Lourdes (OLOL) is a leading Irish hospital in the implementation of Bare Below the Elbows (BBTE) policy, however surgical attire is not standardised and there is great variability in attire worn on wards. We aimed to evaluate patients attitude towards surgeons attire in OLOL.

Methods: A prospective survey of adult surgical in-patients was conducted from October 2013 to February 2014. A twelve-question questionnaire was used as data collection tool, using a five point Likert scale to assess patients response to each question. Data were collected on patient demographics, patients level of trust and confidence based on different surgical attire, and patients perception of different attire worn by surgical teams. Results: There were 150 completed surveys during the study period with a male to female ratio of $44 \%$ to $56 \%$ respectively. The mean patient length of in-hospital stay (LOS) was 4.7 days (range 1-22). The most commonly represented age group was $30-40$ years (18\%), with a comparable spread among all age groups. The majority of patients found the attire worn by surgeons on the ward to be very appropriate (93\%). Majority of responders believed scrubs to be the most appropriate attire for surgeons on wards (39\%), followed by shirt and tie with white coat (38\%) followed by short sleeved shirt and no tie (18\%). Shirt and tie with white coat had a positive effect on patients trust in $63 \%$ of responders, a negative effect in $10 \%$ and no effect in $26 \%$. Scrubs had a positive effect on patients trust in $63 \%$, negative effect in $11 \%$ and no effect in $25 \%$. Short sleeved shirt and no tie had a positive effect in $44 \%$, negative effect in $25 \%$ and no effect in $30 \%$ of patients.

Conclusion: Patients in OLOL find attire worn by surgeons to be appropriate. Shirt and tie with white coat or scrubs remains the patient's choice attire for surgeons. Shirt and tie with white coat or scrubs has a more positive effect on trust of patients compared to short sleeved shirt and no tie.

Keywords: Surgical Attire, Infection Control, Bare Below the Elbows (BBTE)

Copyright: $\odot 2015$ by Kerman University of Medical Sciences

Citation: Meshkat B, Bass GA, Matcovici M, Farnes Z, Buckley C, Al Saffar O, et al. Patients attitude towards surgeons attire in Our Lady of Lourdes Hospital Drogheda. Int J Health Policy Manag 2015; 4: 217-220. doi: $10.15171 /$ ijhpm.2015.31
\end{abstract}

Article History:

Received: 13 December 2014 Accepted: 11 February 2015 ePublished: 15 February 2015

\section{Key Messages}

Implications for policy makers

This study highlights how the introduction of Bare Below the Elbows (BBTE) policy as a quality improvement measure could potentially have negative effects on patient trust and perception of their attending surgeons. Such far reaching implications of a policy change are often unpredictable, especially when tried and tested policies from one health-jurisdiction are adopted in another where cultural differences may exist. With that in mind, it is important to:

- Audit the effects of a policy change on service users (patients).

- Ensure patients are informed of hospital wide policy change which has direct implications for them.

- Where necessary provide patient information regarding the reason for the policy change.

Implications for public

The level of trust and confidence of patients in their surgeon is often based on the surgeons attire. With the introduction of Bare Below the Elbows (BBTE) policy, patients need to know that the lack of long sleeve shirts, ties and white coats is to protect them by reducing hospital acquired infections. In cases where patients are not satisfied with the outcome of a hospital policy change, they should be encouraged to engage with the policy-makers. Doing so ensures that, not only does the policy change provide the intended systems improvement, but also improves the patient's satisfaction with the services provided.

\section{Background}

A doctor's competence and professionalism is often judged on the basis of attire (1-4). The white coat has been a symbol of the medical profession since it was borrowed from laboratory workers in the mid 19th century and recent studies suggest that the trust and confidence instilled in patients by their use remains to this day (1-4). However, while long sleeved white coats were once the norm for surgeons on the wards, it is now more common to see scrub suits or shirt and tie. This move has been fuelled by concerns regarding the harbouring of

Full list of authors' affiliations is available at the end of the article. 
pathogens on the sleeves of white coats and the associated risk of transmission of infection (5). Although most Irish hospitals have no restrictions on the use of white coats, changes are being brought about due to infection control concerns associated with their use.

On September 2007, the National Health Service (NHS) in England introduced a Bare Below the Elbows (BBTE) policy for all its medical staff (5). These measures included the use of short sleeves, no wristwatches or jewellery, avoidance of ties and long sleeve white coats. These measures were aimed at reducing transmission of pathogens from medical staff to patients, however there is varying evidence to link such transmission to the wearing of ties and long sleeve white coats, bringing into question the effectiveness of such measures in infection control policy $(6,7)$.

The phasing out of white coats for infection control purposes has extended effect on patient perception of their attending physicians. Studies suggest these effects are variable and highly dependent on local culture and surgical speciality (1-5). Our Lady of Lourdes (OLOL) Hospital was a leading hospital in Ireland in adopting a BBTE policy in 2013, with similar aims to the NHS. The objectives of this study were to evaluate patient attitude towards the different surgeons attire in our hospital and establish whether they had a particular preference.

\section{Methods}

A prospective survey of adult surgical patients admitted to OLOL hospital from October 2013 to February 2014 was conducted. Any patient who could not read and answer the questionnaire for any reason was excluded as were patients who were admitted to the emergency department only or had day surgery procedures. Patients were asked to complete the questionnaire on the day of their discharge. They were informed of the anonymous nature of the questionnaire and participation was voluntary.

A twelve-question questionnaire was used to collect data on patient demographics, level of trust and confidence based on different surgical attire, as well as patients perception of different attire worn by surgical teams. Participants were asked to use a five point Likert scale to respond to questions where their opinion was sought, with an open comments box provided if they wanted to elaborate on the response. Table 1 demonstrates an example of the Likert scale used.

Questions one through three were used to obtain information on patient demographics, gender, age group and length of inhospital stay (LOS). Question four asked whether patients were overall satisfied with the care that they received during their stay in the hospital using a five point Likert scale (Table 1). Question five asked participants "how appropriate did you find the clothing worn by the doctors attending you" with $1=$ not at all appropriate and $5=$ extremely appropriate. Participants were asked whether at any point during their hospital stay, they felt that their attending doctor was inappropriately dressed and if so, what were they wearing. For the remaining five questions patients were shown three photographs of different doctors in different attires (Figure 1) and asked to comment on appropriateness of each attire and how each attire affects their level of trust and confidence.

Question eight asked which of the above attire participants felt were most appropriate for their attending doctor to be wearing. Questions nine, ten and eleven asked participants to rate the appropriateness of each attire shown on a five point Likert scale with $1=$ not at all appropriate and $5=$ extremely appropriate. The final question asked participants about how their level of trust of their attending doctor was affected by the different attires with $1=$ extremely negatively, $3=$ no effect on trust and $5=$ extremely positively.

Face and construct validity was assured through a review of the questionnaire by the in hospital research group with representatives from surgery, medicine, hospital management, and infection control specialists. The questionnaire was then pilot tested on ten patients and minor changes made following feedback.

The completed questionnaires were collected in sealed collection boxes. The results were analysed using Stata version 13 and represented using descriptive statistics. To compare the patient preferences for different surgical attires, positive responses ( 4 or 5 on the Likert scale) were summarised and compared to negative responses ( 1 or 2 ). Chi-Square test was then used to compare the patients responses with $P<0.05$ considered statistically significant.

Results

There were 1,387 recorded surgical admissions during the study period and 150 completed surveys with $44 \%$ ( $n=$ 66) male and $56 \%(n=84)$ female. The most commonly represented age group was $30-40$ years at $18 \%(n=12)$, with a comparable spread among all age groups. Figure 2 outlines the age group breakdown of survey participants.

The mean LOS of participants was 4.7 (standard deviation 4.1 days), ranging from 1-22 days. Over all there were no patients who were extremely dissatisfied with the care they received, and most $(69 \%, n=104)$ were extremely satisfied at time of discharge (Table 1). Similarly the majority of patients $(63 \%, n=95)$ found the attire worn by surgeons to be appropriate (Table 2).

When asked whether at any point the patient felt that

Table 1. Patient satisfaction with overall care received

\begin{tabular}{lc}
\hline 1. Extremely dissatisfied & $0 \%$ \\
\hline 2. Dissatisfied & $1 \%(n=2)$ \\
3. Neither satisfied nor dissatisfied & $9 \%(n=4)$ \\
4. Satisfied & $20 \%(n=30)$ \\
5. Extremely satisfied & $69 \%(n=104)$ \\
\hline
\end{tabular}
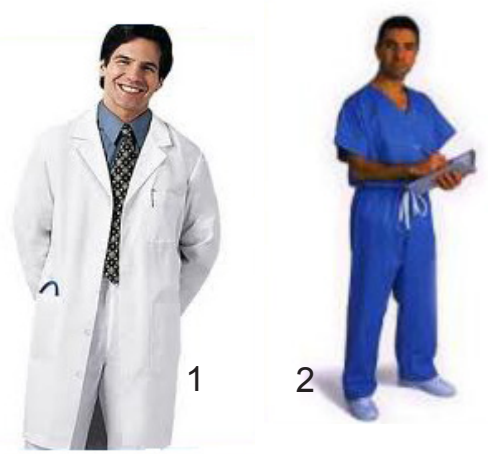

3

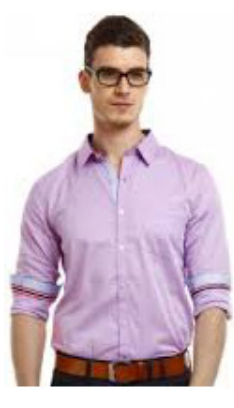

Figure 1. Different surgical attire shown to survey participants 
their attending surgeon was inappropriately dressed, 97\% $(n=145)$ of responders felt that their attending surgeon was appropriately dressed and 3\% $(n=4)$ felt they were inappropriately dressed. Only one survey participant did not respond to the question. The four patients who felt their attending surgeon was inappropriately dressed, elaborated in the free text box with one participant commenting that scrubs were inappropriate on the ward, one commenting that casual clothes was inappropriate and the remaining two commenting that "civilian clothes" was inappropriate for their surgeon to be wearing on the ward. Patient satisfaction was not found to correlate with an assessment of inappropriate dress as none of the patients who rated their surgeons attire as inappropriate reported dissatisfaction with care (Likert scale 3 or less), and this did not differ significantly with patients who rated their surgeons attire as appropriate (Chi-Square test, $P=0.79$ ).

When asked about which of the attires shown in the photographs was most appropriate for the surgeons to be wearing, $42 \%(n=63)$ felt outfit 1 was most appropriate, $44 \%$ $(n=66)$ felt outfit 2 was most appropriate and $14 \%(n=21)$ felt outfit 3 was most appropriate. Subsequently when rating the appropriateness of each outfit on a five point scale, 35\% $(n=53)$ found outfit 1 extremely appropriate, 50\% $(n=75)$ found outfit 2 extremely appropriate and $21 \%(n=32)$ found outfit 3 extremely appropriate. Table 3 outlines the patient responses to appropriateness of each outfit.

When comparing the appropriateness of the different attires, surgical scrubs were thought to be most appropriate by the majority of patients with $71 \%$ finding it either appropriate or extremely appropriate (score of 4 or 5 on Likert scale). This compared to $65 \%$ for shirt and tie with white coat and $38 \%$ for short sleeve shirt, no tie and no white coat. The clear

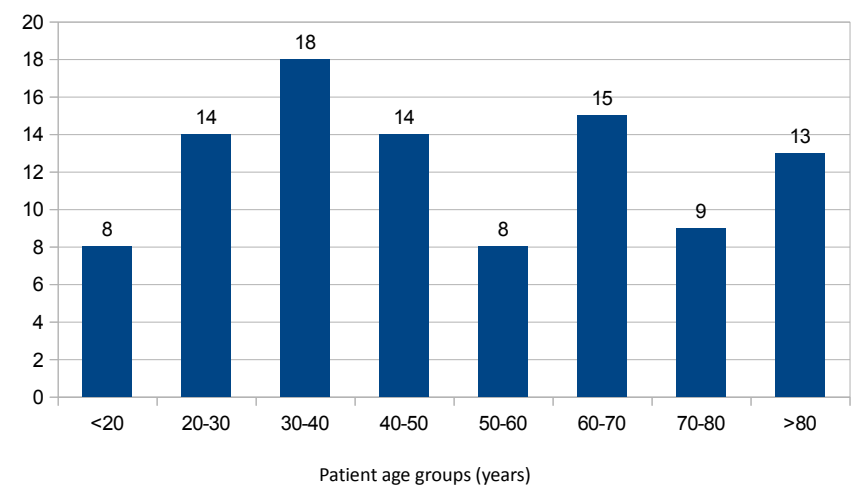

Figure 2. Age group breakdown of surveyed patients
Table 2. Patient perception of surgeons attire

\begin{tabular}{lc}
\hline 1. Not at all appropriate & $1 \%(n=2)$ \\
2. Not appropriate & $0 \%(n=0)$ \\
3. Neither appropriate nor inappropriate & $5 \%(n=8)$ \\
4. Appropriate & $29 \%(n=44)$ \\
5. Extremely appropriate & $63 \%(n=95)$ \\
\hline
\end{tabular}

preference for surgical scrubs was found to be statistically significant when compared to shirt and tie with white coat $(P=0.04)$ and short sleeve shirt without tie or white coat $(P<0.001)$. There was a further clear preference by patients for shirt and tie with white coat compared to short sleeve shirt without tie or white coat $(P<0.001)$.

Statistically significant difference was also noted between what patients felt was the most appropriate attire for their surgeon to be wearing with the most positive effect on their level of trust. Surgical scrubs had the most positive effect on patients level of trust, with $44.3 \%$ of responders finding it to have extremely positive effect on their level of trust, compared to $37.9 \%$ for shirt and tie with white coat and $25 \%$ for short sleeve shirt without tie or white coat. Table 4 outlines the patients level of trust based on the different attire. Comparing the positive effect on trust between the different attires, there was a statistically significant positive effect on patient level of trust for wearing shirt and tie with white coat when compared to short sleeve shirt without tie or white coat $(P<0.01)$. Similarly there was more positive effect on patient level of trust if wearing surgical scrubs compared to short sleeve shirt without tie or white coat $(P<0.01)$. However there was no difference in positive effect on level of trust between surgical scrubs or shirt and tie with white coat $(P=0.99)$.

\section{Discussion}

Hospital acquired infections are costly to healthcare services and can be devastating to patients (8). Strategies to minimise such infections are therefore crucial in providing a safe and efficient healthcare service. The introduction of the BBTE policy in OLOL hospital is one such strategy. Studies to date suggest patients preferences regarding attire worn by hospital doctors varies depending on speciality and cultural background of patients (1-5,9-18). Our surveyed patient population had a clear preference for surgical scrubs over shirt and tie with white coat and short leave shirt without white coat for their attending surgeon to be wearing. The wearing of scrubs or white coat over shirt and tie had a similar positive effect on trust, while wearing of short sleeve shirt without tie or white coat appeared to have a more negative effect on patient trust.

Table 3. How appropriate patients find each outfit for their attending surgeon to be wearing

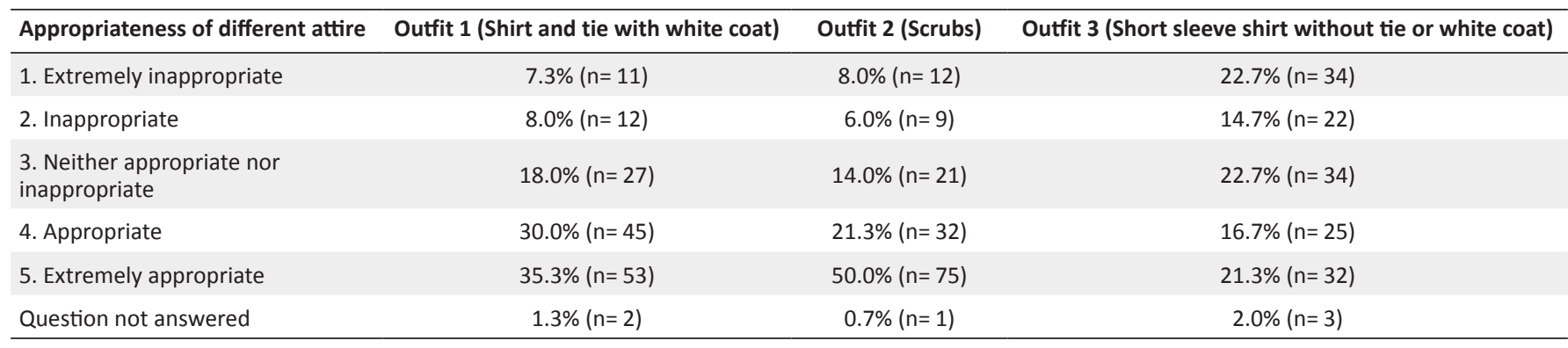


Table 4. Patients level of trust based on the different attire

\begin{tabular}{lccc}
\hline $\begin{array}{l}\text { Attire effect on patient } \\
\text { trust }\end{array}$ & Outfit 1 & Outfit 2 & Outfit 3 \\
\hline 1. Extremely negatively & $4.3 \%(n=6)$ & $2.1 \%(n=3)$ & $11.8 \%(n=17)$ \\
2. Negatively & $5.7 \%(n=8)$ & $9.0 \%(n=13)$ & $13.2 \%(n=19)$ \\
$\begin{array}{lccc}\text { 3. Neither negative - nor } \\
\text { positively }\end{array}$ & $26.4 \%(n=37)$ & $25.0 \%(n=36)$ & $29.9 \%(n=43)$ \\
4. Positively & $25.0 \%(n=35)$ & $22.9 \%(n=33)$ & $18.8 \%(n=27)$ \\
5. Extremely positively & $37.9 \%(n=53)$ & $40.3 \%(n=58)$ & $25.0 \%(n=36)$ \\
Question not answered & $0.7 \%(n=1)$ & $0.7 \%(n=6)$ & $1.4 \%(n=2)$ \\
\hline & & &
\end{tabular}

While our surveyed patient population consisted of only 150 patients, this is comparable with other studies (9-17). Based on these data, wearing of surgical scrubs should be adopted as the preferred surgical attire as it complies with BBTE policy and patients expectations of professional attire for surgeons. Alternatively, patients could be educated on the reason for change of surgeons attire as patient attitude towards surgeons attire has been shown to be malleable (19). Such educational initiatives can reduce potential loss of confidence of patients trust.

We acknowledge a number of limitations of this study. The surveyed patient population accounted for just $10.8 \%$ of all recorded surgical admissions but were deemed to be a representative sample of the usual patient population. However it should be highlighted that the hospital record of all admissions includes patients who underwent day case surgery, paediatric surgical admissions, and patients who were admitted under surgical teams for observation or investigations and remained in the emergency department without admission to the ward. These patients would not have been captured by our survey. Surveyed patients were only asked to evaluate male surgical attire, and there was no attempt at evaluation of female attire. As the study was primarily evaluating patients attitude after introduction of the BBTE policy, it was felt that this change in policy would be more noticeable in male attire. Female surgeons can have greater choice of attire which can continue to appear professional and be BBTE compliant. However there remains a need to clarify what female surgical attire is acceptable to our patients. We also acknowledge that the photographs of different attires are of different people (and not the same person in different attire) which might influence the patients preferences and introduce a level of bias.

In conclusion, patients in OLOL find attire worn by surgeons to be appropriate. Shirt and tie with white coat or scrubs remains the patient's preferred attire for surgeons. Shirt and tie with white coat or scrubs has a more positive effect on trust of patients compared to short sleeved shirt and no tie. The survey data provides baseline information on patient preference and allows for further planning when implementing hospital wide policy change.

\section{Ethical issues}

The study protocol was reviewed by the hospital research board and no ethical concerns were raised.

\section{Competing interests}

The authors declare that they have no competing interests.

Authors' contributions

Study design: BM and PG; Data collection: BM, MM, ZF, CB, and OA; Data analysis: $B M, G A B$, and $P G$; Literature review: $B M$ and $M M$; Writing of paper:
BM, GAB, and PG; Feedback and corrections: BM, GAB, MM, ZF, CB, OA, and $P G$.

Authors' affiliations

${ }^{1}$ Our Lady of Lourdes Hospital, Drogheda, Ireland. ${ }^{2}$ Adelade and Meath Hospital, Tallaght, Ireland. ${ }^{3}$ Royal College of Surgeons, Dublin, Ireland.

\section{References}

1. Bond L, Clamp PJ, Gray K, Van Dam V. Patients' perceptions of doctors' clothing: should we really be 'bare below the elbow'? J Laryngol Otol 2010; 124: 963-6. doi: 10.1017/ s0022215110001167

2. Landry M, Dornelles AC, Hayek G, Deinchmann RE. Patient Preferences for Doctor Attire: The White Coat's Place in the Medical Profession. Ochsner J 2013; 13: 334-42.

3. Colt HG, Solot JA. Attitudes of patients and physicians regarding physician dress and demeanor in the emergency department. Ann Emerg Med 1989; 18: 145-51. doi: 10.1016/s01960644(89)80104-0

4. Rehman SU, Nietert PJ, Cope DW, Kilpatrick AO. What to wear today? Effect of doctor's attire on the trust and confidence of patients. Am J Med 2005; 118: 1279-86. doi: 10.1016/j. amjmed.2005.04.026

5. Greham J. Uniforms and workwear: an evidence base for developing local policy. UK: Department of Health; 2007.

6. Munoz-Price LS, Arheart KL, Mills JP, Cleary T, Depascale D, Jimenez A, et al. Associations between bacterial contamination of health care workers' hands and contamination of white coats and scrubs. Am J Infect Control 2012; 40: e245-8. doi: 10.1016/j. ajic.2012.03.032

7. Dancer SJ. Pants, policies and paranoia. J Hosp Infect 2010; 74: 10-5. doi: 10.1016/j.jhin.2009.10.012

8. Klevens RM, Edwards JR, Richards CL, Horan TC, Gaynes RP, Pollock DA, et al. Estimating healthcare-associated infections and deaths in U.S. Hospitals, 2002. Public Health Rep 2007; 122: $160-6$.

9. Kurihara H, Maeno T, Maeno T. Importance of physicians attire: factors influencing the impression it makes on patients, a cross-sectional study. Asia Pac Fam Med 2014; 13: 2. doi: 10.1186/1447-056x-13-2

10. Trowbridge RE, Pearson R. Impact of military physician rank and appearance on patient perceptions of clinical competency in a primary care setting. Mil Med 2013; 178: 994-1001.

11. Najafi M, Khoshadel A, Kheiri S. Preferences of Iranian patients about style of labelling and calling of their physicians. J Pak Med Assoc 2012; 62: 668-71.

12. Nibhanipudi KV, Mason B, Pandey A, Henriquez R, Hassen GW. A study regarding Spanish-speaking parents' preference of physician attire in the pediatric emergency room. Clin Pediatr (Phila) 2013; 52: 593-8. doi: 10.1177/0009922813483001

13. Al-Ghobain MO, Al-Drees TM, Alarifi MS, AL-Marzoug HM, AlMumaid WA, Asiry AM. Patients' preferences for physicians' attire in Saudi Arabia. Saudi Med J 2012; 33: 763-7.

14. Longmuir S, Gilbertson A, Pfeifer W, Olson RJ. Pediatric ophthalmology attire: should we wear a white coat? Insight 2010; 35: 11-3.

15. Yamada Y, Takahashi O, Ohde S, Deshpande GA, Fukui T. Patients' preferences for doctors' attire in Japan. Intern Med 2010; 49: 1521-6. doi: 10.2169/internalmedicine.49.3572

16. Reddy R. Slippers and a white coat? (Hawai'i physician attire study). Hawaii Med J 2009; 68: 284-5.

17. Fischer RL, Hansenn CE, Hunter RL, Veloski JJ. Does physician attire influence patient satisfaction in an outpatient obstetrics and gynecology setting? Am J Ostet Gynecol 2007; 196: 186.e1-5.

18. Sotgiu G, Nieddu P, Mameli L, Sorrentino E, Pirina P, Porcu A, et al. Evidence for preferences of Italian patients for physician attire. Patient Prefer Adherence 2012; 6: 361-7. doi: 10.2147/ ppa.s29587

19. Collins AM, Connaughton J, Ridgway PF. Bare Below the Elbows: A comparative study of a tertiary and district general hospital. Ir Med J 2013; 106: 272-5. 